\title{
Excellence acmeological education for the economics of the future
}

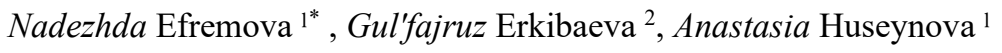 \\ ${ }^{1}$ Don State Technical University, Faculty "Psychology, Pedagogy and Defectology", \\ 344000 Rostov-on-Don, Russian Federation \\ ${ }^{2}$ Khoja Akhmet Yassawi International Kazakh-Turkish University, Turkestan, Kazakhstan
}

\begin{abstract}
The article provides a theoretical analysis of the organisation of "excellence" education in school practice. It presents sound implementation principles of "excellence acmeological" approach to teaching in rural schools and necessary organizational and pedagogical conditions of quality education with the involvement of highly qualified teachers to ensure the educational process and increase the motivation of students to study. The paper proposes organizational and technological implementation model of "excellence acmeological" teaching in rural schools. An objective assessment of the achievement of the expected results is ensured when educational organizations turn to qualified assessment centers in order to assess the level of training among students. Much attention is given to the problems of formation and evaluation of competencies of general secondary education graduates. The excellence acmeological idea of development and self-development directs an individual to become a successful person and a highly qualified specialist.
\end{abstract}

\section{Relevance of the study}

Currently, education is considered as a formation system of intellectual capital of a nation and as one of the main areas for innovation, as it creates the basic conditions for the rapid growth of markets on the basis of continuous updating of technologies and products. Reliance on person's talent, creativity and initiative is regarded as the most important resource of economic and social development of the country. It is the development of a person that represents the main goal and a necessary condition for the progress of modern society and the growth of the nation's well-being. It still represents an absolute national priority in the long term. The task of ensuring equal opportunities in obtaining quality education, regardless of the socio-economic status of students, is among the key objectives for the leading countries of the world [1]. Different foreign and Russian academics conduct studies on excellence in education $[2,3,4]$. The concept of "excellence" serves as a new level of requirements for educational activities, but its study and application in the education system is still in its infancy.

\footnotetext{
* Corresponding author: nefremova61@dstu.edu.ru
} 
Concept of Education Development and developed on its basis Federal Targeted Programme for the Development of Education until 2020 include a number of complex tasks of character building and the formation of human capital as an important factor in the progressive development of the society, the state, and the economy. They provide for implementation of measures to promote scientific, educational and creative activities among children and young people, identification of talented young people, development of infrastructure that provides conditions for training and education of future specialists. The basic principles in the new model of national education are: openness; space for freedom, initiative and motivation; development of the ability to search and update information; high level of innovation [5].

In scientific and methodological terms, the relevance of the study relates to the need to substantiate the theoretical foundations of a new approach to the development of the highlevel education. This requires the establishment of a school network of a new type which implement pilot programmes using the most effective technologies of teaching, upbringing and development of young people through competitive support of school initiatives and network projects, development of inquisitiveness and propensity for innovation.

\section{Results of the study and discussion}

All the studies on education are more or less aimed at improving educational systems and increasing their efficiency. Ensuring an equally high level of educational results for all students, regardless of the location of the school or students contingent, is considered an indicator of effectiveness. If the school ensures the success of learning, improve students' life chances, broaden individual opportunities, regardless of the family context, it may be called effective.

One of the directions of realisation of these tasks is the establishment of innovative schools which are of a type called excellence acmeological education. In a broad sense "excellence acmeological" education may broadly be understood the improvement of organizational and pedagogical conditions of quality training for young people, ensuring not only the achievement of the minimum requirements of the educational standard, but also those ones which significantly exceed them. Excellence means possessing good qualities in high degree, a superiority, or an advantage. Acmeology is a branch of pedagogical psychology that studies the laws and mechanisms of achieving the highest level of individual development; it is the science of improvement, self-improvement and full achievement of self-realisation in life, work and art as the highest achievements of the individual [6]. In many countries educational institutions actively involve the most talented teachers for the organization of educational process as "perfection" tends to generate "perfection" [7].

Excellence acmeological school is an educational organization of high level which provides the necessary conditions for formation and development of students, motivation for higher achievements and the development of leadership qualities necessary for personal growth and effectiveness of the work. This approach takes into account personal and psychological characteristics of students significantly improving the quality of education and stimulating the development process. This is consistent with the requirement of student-centred learning so that it is possible not only to identify and take into account individual characteristics, general and specific inclinations, but also to create optimal conditions for improving positive qualities, neutralizing negative ones, turning inclinations into abilities. At the same time, access to quality education should be free, regardless of the place of residence of students.

This requires the creation of excellence educational conditions. First of all, it includes an individual approach to each student and organisation of the educational process, taking 
into account their opportunities and priorities. That will require educational equipment, computers, access to the Internet, the latest software and multi-media tools; highly qualified teaching staff; comfortable conditions for students in school; compulsory learning of 2 foreign languages starting with primary school. A wide range of innovative teaching technologies, opportunity to choose your own educational route, awareness of your own capabilities to achieve the desired level of education (curriculum is designed considering the interests and wishes of students and parents) are also necessary. It is important to organise a wide range of extracurricular activities including special-interest circles, provide a choice educational routes in accordance with the opportunities and needs of students, and develop learning motivation of students. The modern educational space of the school (library, sports hall, auditorium, student lounge as a place of rest and active games, etc.), competence-oriented educational programmes, as well as a reliable system of assessment and management of the quality of education based on objective results of modern assessment procedures are equally important. In order to develop leadership and organisational skills it is necessary to enhance student government in schools. Cultural and educational work (visiting theaters, museums, art galleries), patriotic education and building an active citizenship are needed for the development of excellence person. Subject-to-subject relations between students and teachers may contribute to personal, social, cognitive and communicative development. And safe educational environment of the school should undoubtedly contribute to maintaining socio-psychological, moral, physical health and psychological stability of all participants in the educational process. One aspect of student success is the social partnership between parents and the school.

An important component of excellence education is the development of regional and ethnic culture of students, their theoretical and practical readiness to work in a multi-ethnic environment. This includes not only systemic ethnopedagogic knowledge, but also the specifics of the ethno-cultural environment, ethnic norms of intercultural interaction. It is necessary to develop ethnically tolerant thinking in the educational process, provide an understanding of the peculiarities of national and universal culture, spiritual and moral traditions of distinct peoples, and differences of their spiritual values. Acquaintance with the values of other nations should be accompanied by a deeper understanding of their own culture, which can be achieved through the development of ethno-cultural competence. The concept of ethno-cultural competence is defined as a component of general communicative competence which provides the acquaintance with foreign cultural values with a deeper understanding of their own culture [8].

All educational activities of such school should be based on the paradigm of competence-based learning and the expected competence model of the graduate, the achievement of which should be formed through a wide range of educational technologies with a consistent assessment of learning outcomes at key stages with their reflection in the portfolio [9].

The establishment of a network of excellence acmeological schools, first of all, involves their formation in rural areas with extensive use of distance learning elements. The materials for distance learning should be prepared by highly qualified teachers, cultural figures, and famous personalities. The transition to an innovative way of school education development in rural areas is connected, first of all, with large-scale investments in human capital. This will require: appropriate material and technical school equipment and the creation of modern information and communication environment; development of distance learning programs: providing feedback through resource centers and a coordination center for distance learning management; preparation of online classes schedule for the network of rural schools. Integration of educational areas and opportunities of schools of the same type is necessary for the networking so that it will be possible to focus on individual characteristics and the needs of students. It is important to provide retraining and further 
training for teachers and principals; modernize general education schools by creating there conditions for excellence learning, including distance education. In the new model (Fig. 1) students should develop their individual educational routes and become mobile choosing various disciplines of supplementary education and opportunities to form their personal competencies.

\section{Model structure of "excellence acmeological" education}

Regulatory and legal
status of forms and
methods of complex
full-time distance
learning under the
"excellence"

\section{Organizational and pedagogical conditions for "excellence acmeological" education}

Providing the requirements for the high level results of mastering the educational programs by students. Legal and methodological support of complex full-time distance learning of young people in rural schools. Involvement of highly qualified specialists for the development of educational programs and teaching online. Organization of training courses for teachers of rural schools, advisory assistance for teachers and students from highly qualified specialists in the field of education.
Material,
technological,
information and
communication
conditions for
distance training

Methods of "excellence-acmeological" education
Active educational technologies, individual and group project activities, modeling,
preparing presentations, independent assessment of achievements, self-learning, self-
control and mutual control, reflection, analysis of achievements and difficulties, search
for ways to eliminate shortcomings.

\section{Assessment of the results of "excellence-acmeological" education}

The use of modern theory and practice of pedagogical measurements, development and application of quality control and evaluation tools and techniques, the solution of complex competence-oriented tasks, assessment of the results via educational audit by independent professional assessment institutions.

\section{Quality assessment criteria for "excellence-acmeological" education}

Compliance of achievements with the expected results, positive dynamics of students' achievements, increase of learning motivation, educational activities and selfdetermination, satisfaction of students and parents with the quality of education, increase in the number of students wishing to study under the "excellence" programmes

Fig. 1. "Excellence-acmeological" education model

Optimization of the acmeological education process requires, first of all, the fulfillment of the basic conditions: development of motivation to learn and motivation to work independently. In acmeology, the needs of self-development and self-improvement are considered as integrative acmeological qualities that ensure the intellectual maturity of 
students. The acmeological components of the learning outcomes are the basic elements of the development of individual characteristics, properties and qualities necessary for the further development [10]. The expected result of education in excellence acmeological school is the achievement of social maturity of graduates, providing readiness for life selfdetermination, professional and personal development, the implementation of an individual programme of success in socially and personally useful activities, and the use of developed leadership qualities.

In addition to learning conditions, it is necessary to ensure an objective quality assessment of the expected results. For this purpose, it is important to develop a system of educational audit where the assessment is made by qualified assessment centres under the outsourcing contract and educational organizations receive and use these assessments solely for their purposes as a reliable feedback for managing the educational process according to its results. Outsourcing of quality assessment of education is the delegation of control and evaluation authority to a specialised organisation which will not only provide a qualitative assessment of the achievements, but also clear the teacher's schedule.

The organization of the processes described above is possible only by means of coordinated actions and regulatory support from the federal and regional education authorities, certain financial costs for the creation of conditions for targeted distance learning and independent assessment of students' achievements. Nevertheless, the eventual benefit in the reproduction of intellectual potential must be fully recouped.

Conclusion. The emerging need for excellence acmeological education is attributable to the heterogeneity of learning conditions of students from urban and rural areas. Such organisations require theoretical understanding, analysis and research of domestic and international experience. Development and implementation of such projects in Russian rural schools require the development of scientific recommendations and practical testing. Implementation of complex full-time distance learning in a rural school will provide an opportunity to take a pedagogically competent and effective approach to the problems of quality training of young people and equal opportunities in learning and in determining the future life trajectory.

\section{References}

1. Providing equal educational opportunities for children: sourcebook. Commission of the Civil Chamber of the Russian Federation on the development of education (HSE Publishing House, Moscow, 2012)

2. M. Brusoni, R. Damian, J. Griffol Sauri, S. Jackson, Komurcugil, Malmedy M., O. Matveeva, G. Motova, S. Pisarz, P. Pol, A. Rostlund, E. Soboleva, O. Tavares, L. Zobel, The concept of Excellence in higher education (ENQA occasional paper, Brussels, 2014)

3. O.A. Matveeva, Kazan Pedagogical Journal. 4, 118-127 (2014)

4. O.A. Matveeva, Kazan Pedagogical Journal. 5, 108-115 (2014)

5. The Concept of Federal Targeted Programme for the Development of Education for 2016-2020 years. http://tovievich.ru

6. B.G. Ananiev, Man as a subject of knowledge (Piter, St. Petersburg, 2010)

7. E.I. Pilyugina, L.V. Vernienko, N.D. Suhoveeva, Educ. and upbringing. 3, 44-46 (2015)

8. G.G. Erikabaeva, Role of multilingualism in the development of national cultures (Balasagyn Kyrgyz National Univer. Bishkek, 2014)

9. N.F. Efremova. Competencies in education: formation and evaluation (National Education, Moscow, 2012)

10. E.I. Pilyugina, L.V. Vernienko, N.D. Suhoveeva. Education and upbringing. 3, 44$46(2015)$ 